\section{Cosci ech}

p-ISSN: 2723-567X

e-ISSN: 2723-5661
Jurnal Computer Science and Information Technology

(CoSciTech)

\author{
http://ejurnal.umri.ac.id/index.php/coscitech/index
}

\title{
Peramalan kedatangan wisatawan mancanegara ke indonesia menurut kebangsaan perbulannya menggunakan metode multilayer perceptron
}

\author{
Muhammad Rifaldo ${ }^{1}$, Harun Mukhtar*2, Reny Medikawati Taufiq ${ }^{3}$, Yoze Rizki ${ }^{4}$ \\ ${ }^{1234}$ Teknik Informatika, Fasilkom, Universitas Muhammadiyah Riau \\ Diterima: Oktober 2021 | Direvisi: November 2021 | Disetujui: Desember 2021 \\ (C2021 Program Studi Teknik Informatika Fakultas Ilmu Komputer, \\ Universitas Muhammadiyah Riau, Indonesia
}

Email: ${ }^{1} 160401007 @$ student.umri.ac.id, ${ }^{2}$ harunmukhtar@umri.ac.id, ${ }^{3}$ renymedikawati@umri.ac.id, ${ }^{4}$ yozerizki@umri.ac.id

\begin{abstract}
Abstrak
Keindahan tempat wisata di Indonesia memiliki daya tarik tertentu bagi wisatawan mancanegara untuk dijadikan sebagai tempat untuk berlibur. Namun jumlah pengunjung perlu diprediksi untuk mengantisipasi terjadinya kenaikan atau penurunan jumlah pengunjung, sehingga negara dapat menentukan kebijakan terhadap perubahan jumlah pengunjung di masa yang akan datang. Peramalan digunakan bertujuan untuk memprediksi pola data yang sebelumnya sehingga dapat diketahui pola data selanjutnya. Multilayer Perceptron(MLP) merupakan salah satu pengembangan neural network yang dapat digunakan untuk pemodelan pada data time series. Beberapa peneliti telah melakukan penelitian dengan metode Multilayer Perceptron dalam melakukan prediksi Adanya sistem Peramalan atau forcesting sangat membantu diera saat ini, dilakukannya peramalan bertujuan untuk memprediksi keadaan yang akan datang. Hasil prediksi, diperoleh akurasi 82\% untuk prediksi wisatawan pada Periode 7 yaitu Bulan September 2020, 97\% untuk Prediksi Periode 8 yaitu Desember 2020 sehingga diperoleh Jumlah Wisatawan Periode 9 yaitu 7.106 Orang.
\end{abstract}

Kata kunci: Prediksi, Multilayer Perceptron, PHP, XAMPP, Wisatawan.

\section{Forecasting the arrival of foreign tourists to indonesia national month using multilayer perceptron}

\begin{abstract}
The beauty of tourist attractions in Indonesia has a certain attraction for foreign tourists to serve as a place for vacation. However, the number of visitors needs to be predicted to anticipate an increase or decrease in the number of visitors, so that the state can determine policies regarding changes in the number of visitors in the future. Forecasting is used to predict previous data patterns so that further data patterns can be known. Multilayer Perceptron (MLP) is a neural network development that can be used for modeling time series data. Several researchers have conducted research using the Multilayer Perceptron method in making predictions. Forecasting systems or forecasting are very helpful in the current era, forecasting aims to predict future conditions. Prediction results, obtained 82\% accuracy for tourist predictions in Period 7, namely September 2020, 97\% for Prediction Period 8, namely December 2020 so that the Number of Tourists for Period 9 is 7,106 people.
\end{abstract}

Keywords: Prediction, Multilayer Perceptron, PHP, XAMPP, Traveler.

\section{Pendahuluan}

Indonesia adalah negara dengan keanekaragaman dan kekayaan alam yang besar. Kekayaan alam Indonesia yang menjadi daya tarik dunia salah satunya yaitu tempat wisatanya, baik darat maupun laut. Keindahan tempat wisata di Indonesia memiliki daya tarik tersendiri bagi wisatawan mancanegara untuk dijadikan sebagai tempat berlibur. Kunjungan wisatawan ke Indonesia meningkat disebabkan oleh banyak faktor, diantaranya biaya perjalanan yang kompetitif, strategi promosi yang terus digencarkan, dan banyaknya rute perjalanan yang memadai. Hal tersebut harus disertai dengan pembangunan fasilitas serta keamanan yang terjamin. Namun jumlah pengunjung perlu diprediksi untuk mengantisipasi terjadinya kenaikan atau penurunan jumlah pengunjung, sehingga negara dapat menentukan kebijakan terhadap perubahan jumlah pengunjung di masa yang akan datang. Misalnya untuk menyeimbangkan keuangan negara agar tidak mengalami penurunan apabila terjadi pengurangan jumlah pengunjung, serta dapat mengatur keuangan negara apabila terjadi kenaikan jumlah pengunjung. Selain itu dapat meningkatkan 
sarana prasarana wisata serta meningkatkan perdagangan di daerah wisata berdasarkan pengalaman di tahun-tahun sebelumnya[1].

Multilayer Perceptron (MLP) merupakan salah satu pengembangan neural network yang dapat digunakan untuk pemodelan pada data time series. Beberapa peneliti telah melakukan penelitian dengan metode Multilayer Perceptron dalam melakukan prediksi. Adanya sistem Peramalan atau forcesting sangat membantu diera saat ini, dilakukannya peramalan bertujuan untuk memprediksi keadaan yang akan datang. Dimana peramalan ini dapat menjadi acuan untuk mengantisipasi bagi pelola atau pihak pariwisata jika terjadi naik turunnya angka atau data yang sudah di prediksi dikemudian hari, didalam dunia pariwisata sendiri pengelola fasilitas pariwisata dapat menjadwalkan pemeliharaan fasilitas sesuai angka atau data yang telah didapatkan setelah dilakukannya peramalan.

\section{Metode Penelitian}

Metodologi penelitian adalah cara yang digunakan untuk menyelesaikan penelitian dengan mengikuti langkah-langkah kerja/skema yang direncanakan agar mendapatkan hasil yang sesuai dengan harapan. Berikut ini adalah gambar alur langkah kerja/skema yang telah direncanakan.

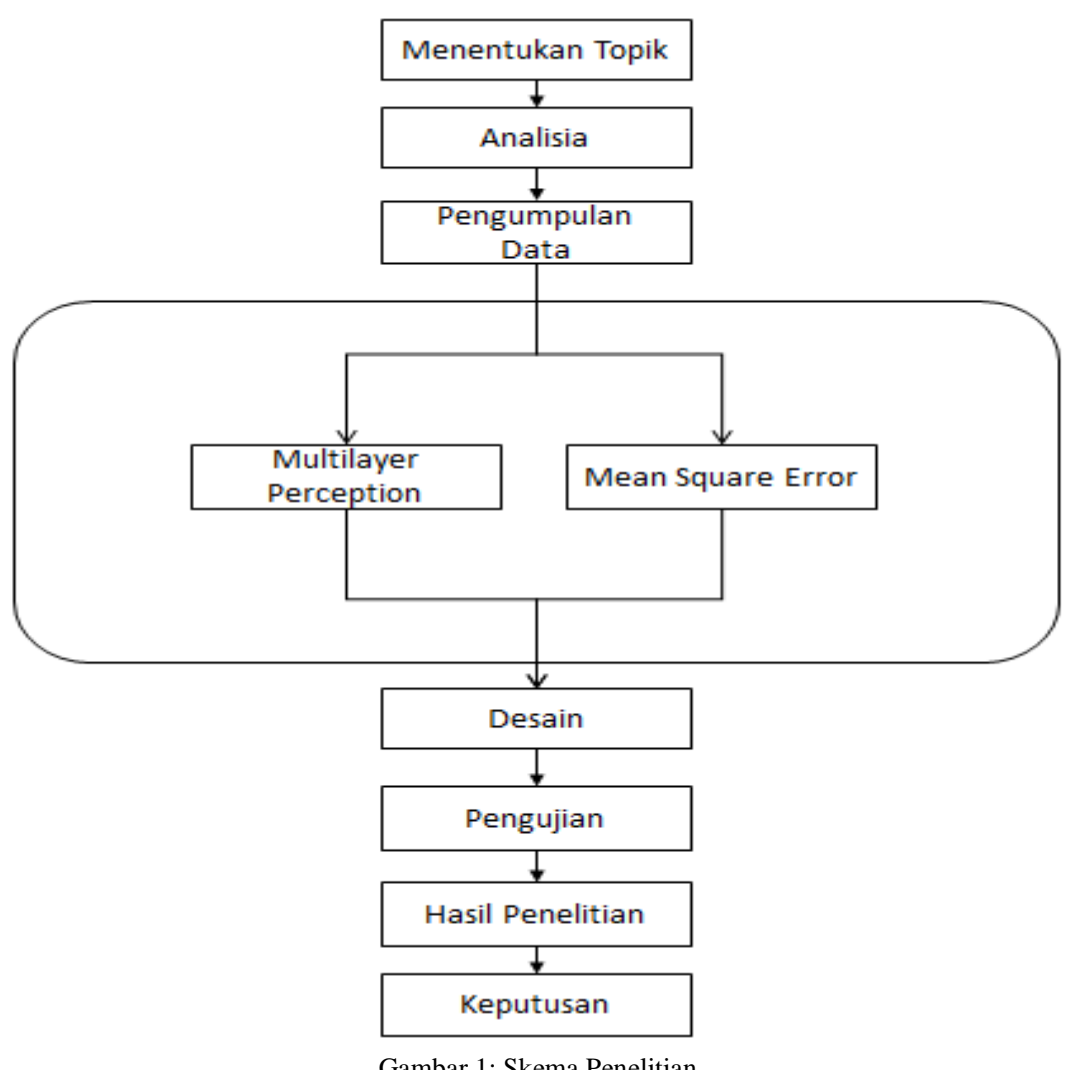

\section{Prediksi}

Prediksi dapat diartikan sebagai suatu proses untuk memperkirakan sesuatu yang mungkin terjadi di masa depan berdasarkan informasi yang dimiliki dari data masa lalu dan masa sekarang yang dilakukan secara sistematis agar tingkat kesalahan nilai prediksi yang diperoleh dapat diperkecil. Suatu prediksi tidak harus memberikan hasil jawaban yang pasti akurat mengenai kejadian yang mungkin terjadi di masa depan, akan tetapi berusaha untuk mendapatkan jawaban sedekat mungkin[2].

\section{Multilayer Perceptron}

Jaringan Syaraf Tiruan (JST) disusun dengan struktur dan fungsi otak manusia sebagai model untuk ditiru. Pada sebuah jaringan syaraf tiruan terdapat sejumlah neuron. Satu neuron bisa terhubung ke banyak neuron lain, dan setiap koneksi (link) tersebut mempunyai bobot (weight). Pembelajaran merupakan karakteristik dasar dari jaringan syaraf biologis. Jaringan syaraf tiruan melakukan proses pembelajaran melalui penyesuaian bobot pada koneksi antar neuronnya[3][4]. 


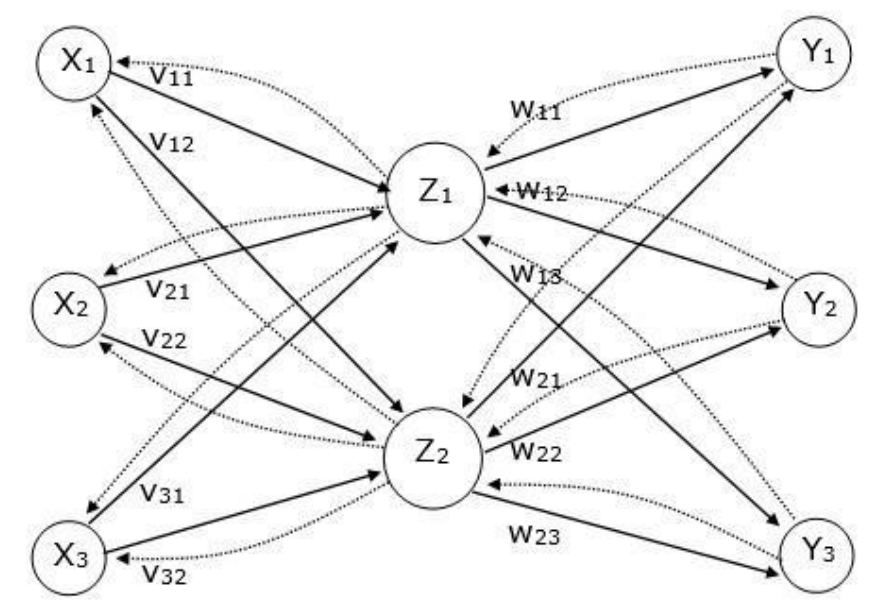

Gambar 2: Ilustrasi Multilayer Perceptron

Secara umum langkah dalam pelatihan Multilayer Perceptron menggunakan Backpropagation adalah sebagai berikut[5] Menentukan jumlah input (pola masukan), hidden layer, dan output (target pelatihan). Memberi nilai awal secara random bagi seluruh bobot antara input-hidden layer dan hidden-output layer. Melakukan Feedforward Tiap unit input (x i ) menerima sinyal input dan sinyal tersebut dikirimkan pada seluruh unit pada hidden layer. Tiap unit pada hidden layer $\left(Z_{-} i_{j}\right)$ menjumlahkan sinyal-sinyal input terbobot. Gunakan fungsi aktivasi untuk menghitung sinyal outputnya. Kirimkan sinyal tersebut ke semua unit di output layer. Tiap unit pada output layer $\left(\mathrm{Y}_{-} \mathrm{in}_{\mathrm{k}}\right)$ menjumlahkan sinyal-sinya input terbobot. Gunakan fungsi aktivasi untuk menghitung sinyal outputnya. Melakukan Backpropagation. Tiap unit pada output layer $\left(\mathrm{y}_{\mathrm{k}}\right)$ menerima target pola yang dengan berhubungan dengan pola input pembelajaran, hitung informasi errornya. Kemudian hitung koreksi bobot (yang nantinya akan digunakan untuk memperbaiki nilai $\mathrm{w}_{\mathrm{jk}}$ ). Hitung juga koreksi bias (yang nantinya akan digunakan untuk memperbaiki nilai $\left.\mathrm{w}_{0 \mathrm{k}}\right)$. Kirimkan $\delta_{\mathrm{k}}$ ke unit yang berada dilapisan bawahnya. Tiap unit pada hidden layer $\left(Z_{-}\right.$in $\left.\mathrm{j}\right)$ menjumlahkan delta inputnya (dari unit yang berada pada lapisan atasnya). kalikan nilai ini dengan turunan dari fungsi aktivasinya untuk menghitung informasi error. kemudian hitung koreksi bobot (yang nantinya akan digunakan untuk memperbaiki nilai $\mathrm{v}_{\mathrm{ij}}$ ). Hitung juga koreksi bias (yang nantinya akan digunakan untuk memperbaiki nilai $\mathrm{v}_{0 \mathrm{j}}$ ). Tiap unit output (y_in $\mathrm{k}$ ) memperbaiki bias dan bobotnya. tiap unit tersembunyi $\left(\mathrm{z}_{-} \mathrm{in}_{\mathrm{j}}\right)$ memperbaiki bias dan bobotnya. Langkah selanjutnya sampai pada penentuan minimum error dan maksimum error.

$$
\begin{aligned}
& z_{-} i n_{j}=V_{0 j}+\sum_{i=1}^{n} x_{i} v_{i j} \\
& z_{j}=f\left(z_{-} i n_{j}\right) \\
& y_{-} i n_{k}=w_{0 j}+\sum_{i=1}^{n} z_{i} w_{j k} \\
& y_{k}=f\left(y_{-} i n_{k}\right) \\
& \delta_{k}=\left(t_{k}-y_{k}\right) f^{\prime}\left(y_{-} i n_{k}\right) \\
& \Delta w_{j k}=\alpha \delta_{k} z_{j} \\
& \Delta w_{0 k}=\alpha \delta_{k} \\
& \delta{ }_{-}^{i n_{j}}=\sum_{k=1}^{m} \delta_{k} w_{j k} \\
& \delta_{j}=\delta_{-} i n_{j} f^{\prime}\left(z z_{-}{ }^{i n_{j}}\right) \\
& \Delta v_{i j}=\alpha \delta_{j} x_{i}
\end{aligned}
$$




$$
\begin{gathered}
\Delta v_{0 j}=\alpha \delta_{j} \\
w_{j k}(\text { baru })=w_{j k}(\text { lama })+\Delta w_{j k} \\
v_{i j}(\text { baru })=v_{i j}(\text { lama })+\Delta v_{i j}
\end{gathered}
$$

Dimana z_in merupakan Bobot sinyal unit tersembunyi, z merupakan Keluaran unit tersembunyi, y_in merupakan Bobot sinyal lapisan keluaran, y merupakan Keluaran unit keluaran, $\delta$ merupakan Kesalahan, $\Delta$ w merupakan Koreksi bobot unit keluaran, $\Delta \mathrm{v}$ merupakan Koreksi bobot unit tersembunyi, $\mathrm{X}_{\mathrm{i}}$ merupakan Unit ( neuron ) pada lapisan input, n merupakan Jumlah neuron (unit) pada input, $\mathrm{V}$ merupakan Bobot awal masuk ke hidden, $\mathrm{V}_{0}$ merupakan Bobot bias yang menuju ke hidden, $\mathrm{W}$ merupakan Bobot awal hidden ke output, $\mathrm{W}_{0}$ merupakan Bobot bias yang menuju ke output, $\alpha$ merupakan Learning rate / rasio pembelajaran

\section{Evaluasi Error pada Peramalan}

Metode yang sering digunakan untuk mengukur tingkat kesalahan hasil prediksi adalah metode Mean Squared Error (MSE). Secara sederhana metode ini bekerja dengan cara membandingkan seberapa dekat atau seberapa jauh hasil prediksi dari nilai aktual. Cara perhitungannya adalah dengan menjumlahkan selisih antara data aktual dan data prediksi kemudian dibagi dengan jumlah data. Metode ini mengakomodasi tingkat kesalahan prediksi yang besar karena nilai kesalahan tersebut dikuadratkan. Perhitungan metode Mean Squared Error ditunjukkan oleh persamaan berikut[6][7]:

$$
M S E=\frac{\sum_{t=1}^{n}\left(X_{t}-F_{t}^{\prime}\right)^{2}}{n}
$$

Dimana $X_{\mathrm{t}}$ merupakan data aktual, $F_{t}^{\prime}$ merupakan data prediksi, n merupakan jumlah data.

\section{Hasil dan Pembahasan}

\section{1) Pemodelan Data Time Series}

Adapun prediksi yang kita lakukan adalah mencari prediksi kunjungan wisatawan bulan Januari tahun 2021 untuk setiap masingmasing negara. Berikut adalah pembentukan model time series untuk data kunjungan wisatawan negara China :

Tabel_ 1: Jumlah Kunjungan Wisatawan China

\begin{tabular}{|c|c|c|c|}
\hline \multirow{2}{*}{ NO } & \multirow{2}{*}{ BULAN KUNJUNGAN } & \multicolumn{2}{|c|}{ JUMAH WISAWATAN } \\
\cline { 3 - 4 } & & 2019 & 2020 \\
\hline 1 & JAN & 178.665 & 183.685 \\
\hline 2 & FEB & 199.960 & 11.586 \\
\hline 3 & MAR & 167.995 & 4.985 \\
\hline 4 & APR & 170.136 & 1.748 \\
\hline 5 & MEI & 164.936 & 1.965 \\
\hline 6 & JUN & 168.269 & 2.079 \\
\hline 7 & JUL & 193.594 & 2.681 \\
\hline 8 & AGU & 193.859 & 3.635 \\
\hline 9 & SEP & 172.856 & 6.934 \\
\hline 10 & OKT & 160.300 & 6.863 \\
\hline 11 & NOV & 147.334 & 6.481 \\
\hline 12 & DES & 154.175 & 7.126 \\
\hline
\end{tabular}

Pada tabel 2 dilakukan permodelan time series yaitu dengan mengurutkan 3 bulan data kunjungan, dimana bulan sebelumnya ( 2 bulan ) adalah data $\mathrm{x} 1$ dan $\mathrm{x} 2$ lalu targetnya adalah bulan ke 3 yaitu y. sedangkan untuk data yang akan diprediksi adalah kunjunngan wisatawan bulan Januari 2021, dimana data x1 dan x2 nya adalah bulan November 2020 dan Desember 2020. Berikut tabel model time series Jumlah kunjungan wisatawan Negara China: 
Tabel_2: Pemodelan Time Series Kunjungan Wisatawan China

\begin{tabular}{|c|c|c|c|}
\hline NO & $\mathbf{X 1}$ & $\mathbf{X 2}$ & $\mathbf{Y}$ \\
\hline 1 & 178.665 & 199.960 & 167.995 \\
\hline 2 & 170.136 & 164.936 & 168.269 \\
\hline 3 & 193.594 & 193.859 & 172.856 \\
\hline 4 & 160.300 & 147.334 & 154.175 \\
\hline 5 & 183.685 & 11.586 & 4.985 \\
\hline 6 & 1.748 & 1.965 & 2.079 \\
\hline 7 & 2.681 & 3.635 & 6.934 \\
\hline 8 & 6.863 & 6.481 & 7.126 \\
\hline 9 & 6.481 & 7.126 & - \\
\hline
\end{tabular}

\section{2) Normalisasi Data}

Tahap normalisasi data bertujuan untuk mempermudah proses pada jaringan. Normalisasi data dilakukan agar Output hasil pelatihan sesuai dengan fungsi aktivasi yang digunakan. Normaliasi data digunakan dengan mengubah skala fitur, data normalisasi atau disebut dengan perskalaan data antara 0-1 dengan rumus persamaan berikut :

$$
X^{\prime}=\frac{0,8(x-a)}{(b-a)}+0,1
$$

Adapun hasil dari Normalisasi Data dari Tabel 3 adalah sebagai berikut :

Tabel_3: Normalisasi Data Kunjungan Wisatawan China

\begin{tabular}{|c|c|c|c|c|}
\hline NO & $\mathbf{x 1}$ & $\mathbf{x} \mathbf{2}$ & $\mathbf{y}$ & KETERANGAN \\
\hline 1 & 0,815 & 0,900 & 0,772 & TRANING \\
\hline 2 & 0,781 & 0,760 & 0,773 & TRANING \\
\hline 3 & 0,875 & 0,876 & 0,792 & TRANING \\
\hline 4 & 0,741 & 0,689 & 0,717 & TRANING \\
\hline 5 & 0,835 & 0,146 & 0,120 & TRANING \\
\hline 6 & 0,107 & 0,108 & 0,108 & TRANING \\
\hline 7 & 0,111 & 0,115 & 0,128 & TESTING \\
\hline 8 & 0,127 & 0,126 & 0,129 & TESTING \\
\hline 9 & 0,126 & 0,129 & 0,100 & TESTING \\
\hline
\end{tabular}

\section{3) Hasil Prediksi Data Testing}

Dari hasil prediksi Data Testing yang dicari, dilakukan pengecekan Mean Squared Error (MSE) nya serta akurasi dari selislih data prediksi dan data aktual dengan rumus :

$$
M S E=\frac{\sum_{k=1}^{a}\left(t_{k}-y_{k}\right)^{2}}{a}
$$

Tabel_4: Hasil Perhitungan Algoritma MLP Data Testing

\begin{tabular}{|c|c|c|c|c|c|c|c|}
\hline PERIODE & TARGET & OUTPUT & ERROR & HASIL PREDIKSI & $\begin{array}{c}\text { DATA } \\
\text { AKTUAL }\end{array}$ & SELISIH & AKURASI \\
\hline 7 & 0,128 & 0,741 & $-0,614$ & 160.308 & 6.934 & 153.374 & $4 \%$ \\
\hline 8 & 0,129 & 0,743 & $-0,614$ & 160.614 & 7.126 & 153.488 & $4 \%$ \\
\hline 9 & 0,100 & 0,743 & $-0,643$ & 160.626 & - & 160.626 & \\
\hline
\end{tabular}

\section{4) Hasil Pengulangan Perhitungan}

Setelah dilakukan pengulangan sampai mencapai Nilai Epoch ke-2.000 maka diperoleh hasil prediksi berikut : 
Tabel_ 5: Hasil Pengulangan Epoch Ke-2.000

\begin{tabular}{|c|c|c|c|c|c|c|c|}
\hline PERIODE & TARGET & OUTPUT & ERROR & HASIL PREDIKSI & $\begin{array}{c}\text { DATA } \\
\text { AKTUAL }\end{array}$ & SELISIH & AKURASI \\
\hline 7 & 0,128 & 0,123 & 0,005 & 5.684 & 6.934 & 1.250 & $82 \%$ \\
\hline 8 & 0,129 & 0,128 & 0,001 & 6.901 & 7.126 & 225 & $97 \%$ \\
\hline 9 & 0,100 & 0,128 & $-0,028$ & 7.106 & - & 7.106 & $100 \%$ \\
\hline \multicolumn{3}{|c|}{ MSE } & 0,0003 & & & & \\
\hline
\end{tabular}

Dari Tabel 4.9 diatas berdasarkan hasil prediksi, diperoleh akurasi 82\% untuk prediksi wisatawan pada Periode 7 yaitu Bulan September 2020, 97\% untuk Prediksi Periode 8 yaitu Desember 2020 sehingga diperoleh Jumlah Wisatawan Periode 9 yaitu 7.106 Orang. Hasil prediksi dapat dilihat pada Grafik berikut :

Tabel_6: Grafik Hasil Prediksi Data Training

\section{PREDIKSI JUMLAH WISTAWAN}

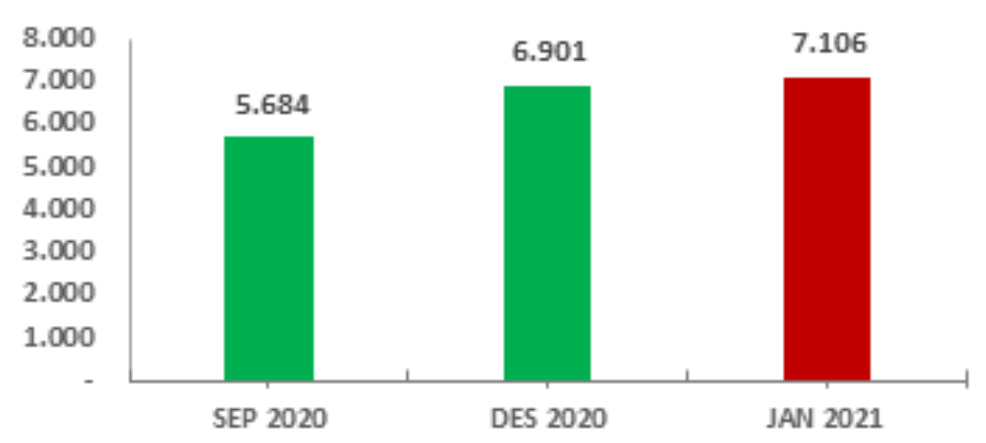

Hasil perhitungan Algoritma Multilayer Perceptron pada dapat disimpulkan sebagai berikut :

a. Berdasarkan hasil prediksi, diperoleh akurasi $82 \%$ untuk prediksi wisatawan pada Periode 7 yaitu Bulan September 2020, 97\% untuk Prediksi Periode 8 yaitu Desember 2020 sehingga diperoleh Jumlah Wisatawan Periode 9 yaitu 7.106 Orang

b. Adapaun Jumlah Iterasi / Epoch pada perhitungan Algoritma Multilayer Perceptron yaitu 2.000 Epoch

c. Nilai MSE yang diperoleh adalah 0.0003 sehingga bisa dikatakan prediksi yang diperoleh sudah akurat.

\section{KESIMPULAN}

Berdasarkan hasil dari penelitian yang telah dilakukan, dapat ditarik kesimpulan yaitu:

1. Metode Algoritma Multilayer Perceptron dapat digunakan untuk memprediksi Jumlah Pengunjung Wisatawan Mancanegara.

2. Hasil dari Prediksi yang dilakukan untuk setiap data pengunjung wisatawan untuk setiap negaranya, memiliki nilai Epoch yang berbeda untuk mencapai akurasi yang maksimal untuk prediksi yang dihitung.

\section{DAFTar PUSTAKa}

[1] T. Kincowati, M. T. Furqon, and B. Rahayudi, "Prediksi Jumlah Kunjungan Wisatawan Mancanegara Ke Indonesia Menggunakan Metode Average-Based Fuzzy Time Series Models,” J. Pengemb. Teknol. Inf. dan Ilmu Komput., vol. 3, no. 6, pp. 5250-5256, 2019.

[2] L. S. Dewi, "Prediksi Harga Saham Perusahaan Kelapa Sawit menggubakan Pemodelan MLP dan RBF," J. Techno Nusa Mandiri, vol. XI, no. 1, 2014.

[3] I. Oktavianti, E. Ermatita, and D. P. Rini, “Analisis Pola Prediksi Data Time Series menggunakan Support Vector Regression, Multilayer Perceptron, dan Regresi Linear Sederhana,” J. RESTI (Rekayasa Sist. dan Teknol. Informasi), vol. 3, no. 2, pp. 282-287, 2019, doi: 10.29207/resti.v3i2.1013.

[4] P. Githa Pratiwi, I. Ketut Gede Darma Putra, and D. Purnami Singgih Putri, "Peramalan Jumlah Tersangka Penyalahgunaan Narkoba Menggunakan Metode Multilayer Perceptron," J. Ilm. Merpati (Menara Penelit. Akad. Teknol. Informasi), vol. 7, no. 2, p. 143, 2019, doi: 10.24843/jim.2019.v07.i02.p06.

[5] Khoirudin, D. Nurdiyah, and N. Wakhidah, "Prediksi Penerimaan Mahasiswa Baru Dengan Multi Layer Perceptron," J. Pengemb. Rekayasa dan Teknol., vol. 14, no. 1, p. 1, 2019, doi: 10.26623/jprt.v14i1.1212. 
[6] Lukman and I. Sunoto, "Komparasi Algoritma Multilayer Perception dan Support Vector Machine dalam Pemilihan Beasiswa," SAP (Susunan Artik. Pendidikan), vol. 2, no. 1, pp. 114-128, 2017, doi: 10.30998/sap.v2i1.1730.

[7] Y. A. Hakim, M. T. Randy Erfa Saputra, S.T., and M. T. Anton Siswo Raharjo Ansori, S.T., "Sistem Pendukung Keputusan Penyiraman Tanaman Cabai Dengan Memanfaatkan Kecerdasan Buatan Menggunakan Algoritma Lstm Decision Support System of Chili Planting Using Artificial Intelligence Using Lstm Algorithm,” vol. 7, no. 2, pp. 49594967, 2020. 